\title{
Trends of Self-Medication Amongst the Patients Visiting the Out-Patient Department of Combined Military Hospital, Lahore
}

\section{Bushra Asif Ali Khan, ${ }^{1}$ Faiza Muzahir, ${ }^{2}$ Sahar Abdul Rauf, ${ }^{3}$ Syeda Rubab Fatima, ${ }^{4}$ Abida Pervaiz, ${ }^{5}$ Sadaf Jamil ${ }^{6}$}

\begin{abstract}
Objective: The purpose of our study was to assess the trends of self-medication practices and to determine the prevalence, characteristics, related factors, and effects of self-medication among the patients conducted. Methods: This descriptive cross-sectional study was on patients of Combined Military Hospital Lahore on a sample size of 365 . The data was collected and entered in a predesigned questionnaire about self-medication later analyzed using SPSS version 17.0.

Results: The prevalence of self-medication was $95.3 \%$ and effectiveness was $87.7 \%$. The common reasons for self-medication were prior knowledge of usefulness of remedy (63.3\%), non-affordability of consultant charges $(18.4 \%)$, and lack of time $(21.9 \%)$. Frequently used medicines included antibiotics $(30.1 \%)$, analgesics $(69.6 \%)$, antipyretics $(51.0 \%)$, and antihistamines $(23.6 \%)$. Respondents claimed to receive information about these drugs from various sources including doctor (38.6\%), previous prescription $(31.8 \%)$, retailer seller $(13.4 \%)$, family/friends (43.6\%), media (7.9\%) and other sources (1.6\%).

Conclusion: It had been concluded that there is a high prevalence of self-medication. There is a need to raise public awareness about the appropriate use in order to prevent potential hazards of self-medication.

Key Words: trends, self-medication, out-patient department

How to cite: Khan B.A.A, Muzahir F, Rauf S.A, Fatima S.R, Pervaiz A, Jamil S. Trends of self- medication amongst the patients visiting the out-patient department of Combined Military Hospital, Lahore. Esculapio.2021.30-33

DOI: https://doi.org/10.51273/esc21.2516
\end{abstract}

\section{Introduction}

$\mathrm{S}^{\mathrm{s}}$ elf-medication refers to intake of medicinal products to treat self- recognized symptoms or the intermittent or continued use of medication prescribed by doctor for chronic or recurring disease. It also involves self-administration of medication to family members especially children and the elderly. ${ }^{1}$

Frequent use of medications like sedatives hypnotics like alprazolam could be addictive in contrast to analgesics or anti-pyretics. The access of over the

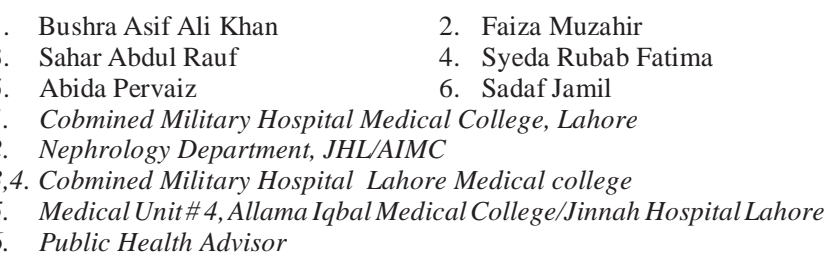

Dr. Bushra Asif Ali Khan, Demonstrator Cobmined Military Hospital Medical College, Lahore.Email: bushraasif.khan5@gmail.com

Submission Date: 1st Revision Date: Acceptance Date: $07-01-2021$ counter medications makes it easier for people to get drug of one's choice. The sale of certain drugs is although prohibited without proper prescription, but people used to get it via unfair means.

Formulations other than allopathic medications like herbal and hakeem medication has no check and unregulated in Pakistan so their consumption is vast. Certain medicines contain impurities and additives that can be injurious to human health. ${ }^{2}$ These medications may also contain certain active harmful ingredients, like nonspecific beta blockers which can produce undesirable effects in certain individuals with disease like allergies, asthma etc. Self-medication involving inadequate and inappropriate dosage, incomplete treatment course and indiscriminate drug use may lead to evolution and rise of antimicrobial resistance.

The prevalence of self-medication ranges from $38.5 \%$ to $92 \%$ in various regions of the world. ${ }^{3}$ The local data is scanty, but it showed prevalence of around $51 \%$ to $84.4 \%$. There is a paradigm shift towards self-medication with an increased number of 
people using medications on their own without proper consultation. ${ }^{4,5}$

Keeping this in mind this study was designed with the sole purpose of finding the trend and prevalence as well the reasons behind the practice of self-medication amongst the population.

The present study was conducted with an intent to find the prevalence, cause of self-medication, different indications, the common factors compelling people to self- medicate and to assess the effectiveness and side-effects of self-medication.

\section{Methods}

This descriptive cross-sectional study conducted at Combined Military Hospital (CMH), Lahore on patients visited the outpatient department (OPD). A total of 365 individuals were recruited for the study via a convenience sampling method from various OPDs in CMH (medicine, surgery, ophthalmology, ENT, dermatology, dentistry, gynecology, pediatrics) irrespective of the underlying disorder that brought them to visit the hospital. A standardized questionnaire deigned included demographic characteristics and questions related to self-medication after taking informed consent. The selected patients were verbally informed about the purpose of the study. They were assured about the confidentiality of their responses and personal information. The respondents were interviewed. The data was entered and analyzed by SPSS version 17.0. Descriptive statistics, including mean, standard deviation, frequency and percentage were used. Analytical statistics including chi square test was used to see the association of self-medication with other variables. P-value of $<0.05$ was considered statistically significant.

\section{Results}

Out of total sample size of 365 , males were $202(55.3 \%)$ and females were 163(44.7\%). The frequency of self-medication remained higher in illiterate than literate group shown in table\#1. $348(95.3 \%)$ patients showed willingness for selfmedication, while $17(4.7 \%)$ didn't use it very often. $320(87.7 \%)$ patients respon-ded in favor of the effectiveness of self-medication, while $45(12.3 \%)$ stated that it wasn't effective.

The most prevalent reason for self-medication was the existing knowledge of remedy $(n=231,63.3 \%)$, followed by patients' lack of time $(\mathrm{n}=80,21.9 \%)$ and high fees of doctor $(n=67,18.4 \%)$. Majority used allopathic medicine $(n=305,83.6 \%)$, while for homeopathic it was $12.6 \%(\mathrm{n}=46)$ and Hakeem's medicine $(n=46,12.6 \%)$. Amongst the drugs used, the most common were analgesics $(n=254,69.6 \%)$, however antipyretics were $51.0 \%(\mathrm{n}=186)$, antibiotics $30.1 \%$ $(n=110)$ and antihistamines $23.6 \%(n=86)$.

Among the drug category, Allopathic medicine showed significant results $(\mathrm{p}=0.001)$. The most significant reason of self-medication was found to be existing

Table 1: Various Demographic Characteristics

\begin{tabular}{cccc}
\hline \multicolumn{2}{c}{ Variable } & Frequency(n) & Percentage(\%) \\
\hline Age Ranges & $10-30$ & 160 & 43.8 \\
& $31-50$ & 150 & 41.1 \\
\multirow{4}{*}{ Gender } & $51-70$ & 50 & 13.7 \\
\multirow{4}{*}{ Qualification } & $>70$ & 5 & 1.4 \\
& Male & 202 & 55.3 \\
& Female & 163 & 44.7 \\
& School Level & 135 & 17.8 \\
& Undergraduate & 111 & 37.0 \\
& Graduate & 36 & 30.4 \\
& Postgraduate & 18 & 4.9 \\
\hline
\end{tabular}

knowledge of remedy $(\mathrm{p}=0.001)$, followed by not enough time ( $p=0.025)$, while high fees of doctor was less significant $(\mathrm{p}=0.045)$. There was high significance for fever $(p=0.001)$, pain $(p=0.001)$ and headache $(\mathrm{p}=0.001)$ while that for Allergy was a little less $(\mathrm{p}=$ $0.014)$

Among the drugs used, Analgesics and Antipyretics were most frequently used for self-medication. They showed the highest significance with $\mathrm{p}$ values of 0.001 each. They were followed by Antibiotics and Antihistamines with $\mathrm{p}$ values of 0.006 and 0.019 respectively. The most significant source of drug information were doctors $(\mathrm{p}=0.001)$ and family/ friends $(\mathrm{p}=0.001)$, followed by previous prescription $(p=0.004)$. The results showed that the number of participants who agreed with the high efficacy of selfmedication were significant with a $\mathrm{p}$ value of 0.001 . Similarly lack of experiencing any side-effects was also a highly significant response.

Among the most prevalent conditions for self-medication were headache $(n=203,55.6 \%)$, fever $(n=195$, $53.4 \%)$, pain $(n=195,53.4 \%)$ and allergy $(n=93$, $25.5 \%$ ). Less prevalent conditions include heartburn $(n=47,12.9 \%)$, cough $(n=37,10.1 \%)$, diarrhea $(n=26$, 
$7.1 \%)$ and others $(n=39,10.7 \%)$.

Patients know which drug to use in self-medication mostly due to family/friends ( $\mathrm{n}=159,43.6 \%)$, doctors $(\mathrm{n}=141,38.6 \%)$, and previous prescription $(\mathrm{n}=$ $116,31.8 \%)$. Less common sources were retailer seller $(n=49,13.4 \%)$, media $(n=29,7.9 \%)$ and others $(\mathrm{n}=6,1.6 \%)$.

Most patients $(\mathrm{n}=216,59.2 \%)$ didn't experience any side effects of self- medication, while those who did mostly complaint about nausea/vomiting $(n=56$, $15.3 \%)$, dizziness $(n=3,9.0 \%)$ and diarrhea $(n=32$, $8.8 \%$ ). Less commonly experienced side-effects include allergic reaction $(n=26,7.1 \%)$, acidity $(n=26$, $7.1 \%)$, headache $(n=18,4.9 \%)$ and others $(n=12$, $3.3 \%)$.

\section{Discussion}

The trend of self-medication is variable ranging from $38.5 \%$ to $92 \%$ in various regions of the world. ${ }^{6}$ Local studies conducted in Pakistan showed prevalence of around $51 \%$ to $84.4 \%$.

In the current study, allopathic medicine remained the mostly used category $(n=305,83.6 \%)$ in contrast with homeopathic and hakeem medications.

The most commonly ailment for self-medication was fever $(\mathrm{n}=195,53.4 \%)$ followed by generalized pain $(n=195,53.4 \%)$ and headache $(n=203,55.6 \%)$. Thus, the most frequently used drugs reported were analgesics $(n=254,69.6 \%)$ followed by antipyretics $(n=186$, $51 \%)$ and antibiotics $(\mathrm{n}=110,30.1 \%)$. The results of our study are in consistent with previous studies which reflected the similar prevalence. ${ }^{7-9}$

$63 \%$ of the participants reasoned that they already had knowledge regarding their remedy and the indications of the specific drug used, $21.9 \%$ of patients indicated lack of time. In addition, $18.4 \%$ of the participants were hindered to visit proper medical facilities due to the inability to afford the high fees charged by the doctors. These factors have been established by previous surveys as well. ${ }^{10}$

We also assessed the sources of information facilitating and encouraging the patients to self-medicate. It was found that the most pivotal role was played by family members and friends $(n=159,43.6 \%)$ in dispensing drug information. This was followed by referral to previous prescriptions $(n=116,31.8 \%)$. Interestingly the role of social media was found to be a contributing factor too $(n=29,7.9 \%) .{ }^{11-16}$
Care must also be exercised to limit the development of antibiotic resistance as a result of increased tendency to self-medicate, an issue of a great concern now. ${ }^{20}$ Studies conducted earlier signify that improper selfmedication can lead to adverse drug reactions, increased morbidity, and mortality in addition to wastage of medical assets. ${ }^{17-20}$

Our present study reflected that a significant percentage of participants $(n=320,87.7 \%)$ were agreed to the effectiveness of self-medication.

Limitations of this study are that this was a crosssectional study where the sample was limited to patients visiting a single hospital located in an urban area, there is a need to collect evidence from rural area as well as the study does not accurately represent the trend across the country. Further as convenience sampling method was used and data collection was not blinded there is a chance of potential bias.

\section{Conclusion}

Self-medication was found to have an alarmingly high prevalence amongst the participants of this survey. However, keeping in mind the potential risks associated with self-medication, there is a need to spread awareness using means of social media, healthcare workers and health awareness campaigns. Efforts in the legislative policies are required to combat the outcome, primarily the disadvantages, caused by the increased trend to self-medicate by the availability of over the counter medicines and recommendations given by the ill-trained personnel at the pharmaceu-tical outlets. There is a need to educate people regar-ding potential hazards of outcomes.

\section{Conflict of interest: None}

\section{References}

1. Bond, C. M. POM to P-implications for Practice Pharmacists. Prim Care Pharm 2001; 2:5-7.

2. Sridhar SB, Shariff A, Dallah L, Anas D, Ayman M, Rao PG. Assessment of Nature, Reasons, and Consequences of Self-medication Practice among General Population of Ras Al-Khaimah, UAE. Int J Appl Basic Med Res. 2018 Jan-Mar;8(1):3-8. doi: 10.4103/ ijabmr.IJABMR_46_17. PMID: 29552527; PMCID: PMC5846215.

3. Ali SE, Ibrahim MI, Palaian S. Medication storage and self-medication behaviour amongst female students in Malaysia. Pharm Pract (Granada). 2010 
Oct;8(4):226-32. doi: 10.4321/s 1886 36552010000400004. Epub 2010 Mar 15. PMID: 25126145; PMCID: PMC4127060.

4. Bowen D, Kisuule G, Ogasawara H, Ch Siregar JP, Williams GA, Hall C, Lingam G, Mann S, Reinstein JA; Couper M, Idänpään-Heikkilä J, Yoshida J. Guidelines for the regulatory assessment of medicinal products for use in selfmedication. Geneva: World Health Organisation; 2000.

5. Abdi A, Faraji A, Dehghan F, Khatony A. Prevalence of self-medication practice among health sciences students in Kermanshah, Iran. BMC Pharmacol Toxicol. 2018 Jul 3;19(1):36. doi: 10.1186/s40360-0180231-4. PMID: 29970167; PMCID: PMC6029137.

6. Badiger S, Kundapur R, Jain A, Kumar A, Pattanshetty S, Thakolkaran N, Bhat N, Ullal N. Selfmedication patterns among medical students in South India. Australas Med J. 2012;5(4):217-20. doi: 10.4066/ AMJ.2012.1007. Epub 2012 Apr 30. PMID: 22848313; PMCID: PMC3395275.

7. James H, Handu SS, Al Khaja KA, Otoom S, Sequeira RP. Evaluation of the knowledge, attitude and practice of self-medication among first-year medical students. Med Princ Pract. 2006;15(4):2705. doi: 10.1159/000092989. PMID: 16763393.

8. Banerjee I, Bhadury T. Self-medication practice among undergraduate medical students in a tertiary care medical college, West Bengal. J Postgrad Med. 2012 Apr-Jun; 58(2):127-31. doi: 10.4103/00223859.97175. PMID: 22718057.

9. Zafar SN, Syed R, Waqar S, Zubairi AJ, Vaqar T, Shaikh M, Yousaf W, Shahid S, Saleem S. Selfmedication amongst university students of Karachi: prevalence, knowledge and attitudes. J Pak Med Assoc. 2008 Apr;58(4):214-7. PMID: 18655436.

10. Abay SM, Amelo W. Assessment of self-medication practices among medical, pharmacy, and health science students in gondar university, ethiopia. J Young Pharm. 2010 Jul;2(3):306-10. doi: 10.4103/ 0975-1483.66798. PMID: 21042491; PMCID: PMC2964771.

11. Parmar Z, Malhotra S, Patel V. (2017). Prevalence and pattern of self-medication in elderly individuals. Intern J of Basic \& Clinical Pharm. 2015; 4(6), 10951099. doi:10.18203/2319-2003.ijbcp20151338

12. Mannat K B, Singh R, Singh A, Bhardwaj B. Knowledge, Attitude and Practice of self- medication among undergraduate medical students of Punjab. JMR
2017; 3(3): 151- 154

13. Shankar PR, Partha P, Shenoy N. Self-medication and non-doctor prescription practices in Pokhara valley, Western Nepal: a questionnaire-based study. BMC Fam Pract. 2002 Sep 17;3:17. doi: 10.1186/14712296-3-17. PMID: 12236905; PMCID: PMC130019.

14. Berzanskyte A, Valinteliene R, Haaijer-Ruskamp F M, Gurevicius R, Grigoryan L. Self-medication with antibiotics in Lithuania. Int $\mathrm{J}$ Occup Med Environ Health. 2006;19: 246-53.

15. Julie M, Donohue, Marisa C, Meredith B, Rosenthal. A Decade of Direct-to-Consumer Advertising of Prescription Drugs. N Engl J Med 2007; 357:673681: 10.1056/NEJMsa070502

16. Burak LJ, Damico A. College students' use of widely advertised medications. J Am Coll Health 2000; 49: $118-21$

17. Komolafe OO. Antibiotic resistance in bacteria - an emerging public health problem. Malawi Med J. 2003 Jun;15(2):63-7. doi: 10.4314/mmj.v15i2. 10780. PMID: 27528961; PMCID: PMC3345436.

18. Roca I, Akova M, Baquero F, Carlet J, Cavaleri M, Coenen S, Cohen J, Findlay D, Gyssens I, Heuer OE, Kahlmeter G, Kruse H, Laxminarayan R, Liébana E, López-Cerero L, MacGowan A, Martins M, Rodríguez-Baño J, Rolain JM, Segovia C, Sigauque B, Tacconelli E, Wellington E, Vila J. The global threat of antimicrobial resistance: science for intervention. New Microbes New Infect. 2015 Apr 16;6:22-9. doi: 10.1016/j.nmni.2015.02.007. Erratum in: New Microbes New Infect. 2015 Nov;8:175. PMID: 26029375; PMCID: PMC4446399.

19. Bengtsson-Palme J, Kristiansson E, Larsson DGJ. Environmental factors influencing the development and spread of antibiotic resistance. FEMS Microbiol Rev. 2018 Jan 1;42(1): fux053. doi: 10.1093/ femsre/ fux053. PMID: 29069382; PMCID: PMC5812547.

20. Ocan M, Obuku E A, Bwanga F, Akena D, Richard S, Ogwal-Okeng J, CelestinoObua. Household antimicrobial self-medication: a systematic review and meta-analysis of the burden, risk factors and outcomes in developing countries.BMC Public Health. 2015; 15: 742. doi: 10.1186/s12889-015-2109.

\section{Authors Contribution}

: Conceptionlization of Project

RAS : Data Collection

MF: Statistical Analysis

KAAB,PA,JS: Writing of Manuscript 
Esculapio - Volume 16, Issue 042020 - www.esculapio.pk - 5 